\title{
BLACK-VELDTRUP, Mechthild, Kaiserin Agnes (1043-1077)
}

\section{Patrick Corbet}

\section{OpenEdition}

Journals

Édition électronique

URL : http://journals.openedition.org/ifha/1504

DOI : 10.4000/ifha. 1504

ISSN : 2198-8943

\section{Éditeur}

IFRA - Institut franco-allemand (sciences historiques et sociales)

Référence électronique

Patrick Corbet, «BLACK-VELDTRUP, Mechthild, Kaiserin Agnes (1043-1077)», Revue de l'IFHA [En ligne], Date de recension, mis en ligne le 01 janvier 1997, consulté le 22 septembre 2020. URL : http:// journals.openedition.org/ifha/1504; DOI : https://doi.org/10.4000/ifha.1504

Ce document a été généré automatiquement le 22 septembre 2020

(CIFHA 


\title{
BLACK-VELDTRUP, Mechthild, Kaiserin Agnes (1043-1077)
}

\author{
Patrick Corbet
}

C'est un mouvement caractéristique de la médiévistique récente que de redonner leur place aux personnalités féminines du haut Moyen Age, restées longtemps dans l'ombre de leurs époux et de leurs fils. Sans revenir ici sur le cas de Théophano, fêtée en 1991, on citera volontiers celui de Béatrice de Toscane, objet du livre bienvenu d'Elke GOEZ (chez J. Thorbecke, Sigmaringen 1995). Avec l'ouvrage de M.B.-V., c'est l'impératrice Agnès, qui se trouve scrutée par l'érudition. Nul n'a oublié le destin difficile de cette princesse d'origine poitevine, mariée en 1043, en une union contestée, car consanguine, à l'empereur Henri III, régente six années avant qu'un parti d'opposants, conduit par Annon de Cologne, lui ravisse son fils à Kaiserswerth (1062), la poussant à une sorte de retraite prise en Italie, au milieu du clergé réformateur, jusqu'à sa fin à Rome en 1077.

Les axes de l'étude de M.B.-V. ont été dictés par l'historiographie. Agnès avait fait l'objet en 1933 d'une biographie due à M.L. BULST-THIELE, un travail qui garde toute sa valeur de consultation. Dans ces conditions, il ne pouvait être conseillé de refaire une nouvelle analyse d'ensemble. M.B.-V. a donc organisé son propos autour de quelques grandes questions fondées sur un réexamen de la documentation, en particulier sur une étude plus complète des diplômes impériaux et la prise en compte des sources mémoriales, inexploitées par sa devancière. Cinq chapitres ont été ainsi définis: 1 . Sur une centaine de pages, terminées aux p. 62-100 par un utile régeste, une reprise de l'itinéraire de la souveraine, comparée aux données des diplômes, qui aboutit à majorer l'influence d'Agnès, avant comme après la mort de son mari. 2. Les aspects mémoriaux et le rôle des églises de Spire et de Goslar dans la conscience familiale des Saliens. 3. L'examen de la politique saxonne, traitée en 130 pages et constituant le coeur de l'ouvrage. Agnès semble avoir mené auprès des élites de ce regnum une politique habile, plus souple que celle de son mari et, après elle, de son fils. Grâce à des mesures prudentes, notamment d'opportunes rétrocessions de domaines, elle évita avec sagesse toute confrontation avec la turbulente aristocratie régionale. 4. L'action réformatrice, renouvelée par l'apport des documents nécrologiques. L'impératrice s'y révèle à l'origine d'importantes innovations: les débuts de la réforme canoniale en Allemagne, 
la diffusion de l'influence clunisienne et des coutumes de Fruttuaria. 5. Le livre se termine par l'étude du retrait graduel des responsabilités. L'auteur attribue un grand rôle au choix malheureux de l'antipape Cadalus lors de l'élection pontificale de 1061, choix qu'Agnès regretta amèrement par la suite. On notera aussi une réinterprétation $\mathrm{du}$ drame de Kaiserswerth, qui aura été avant tout dirigé contre l'évêque Henri d'Augsbourg, devenu trop puissant à ses côtés.

Ce bien court résumé donne une image appauvrie du contenu très riche de ce livre. M.B.-V. entend y réagir contre l'impression de passivité et d'échec qui dominait dans l'ouvrage de 1933. Même si la démonstration convainc souvent, on ne fera pas de cette réappréciation l'apport majeur du travail: on cherchera celui-ci dans les analyses soignées qu'il offre de tous les problèmes abordés. Si elles demeurent soumises à la controverse savante, elles devront être prises en considération pour toute recherche sur les décennies mouvementées du milieu du XIe s.

Patrick CORBET 